\title{
A CRISE DO TRÂNSITO EM SÃO PAULO E SEUS CUSTOS CIRCULAÇÃO DO TRÂNSITO
}

I POR MARCOS CINTRA

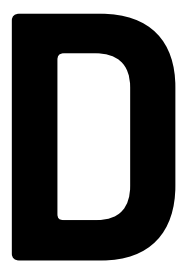
e acordo com o relatório State of the World's Cities 2012-2013, elaborado pela Organização das Nações Unidas (ONU), os centros urbanos (e não os países) vão comandar a criação de riquezas no planeta. Para reforçar essa ideia, a entidade afirma que "o bom ambiente urbano é tão determinante no século XXI como a matéria-prima foi para a indústria no século XIX”.

Infraestrutura, produtividade econômica, qualidade de vida, inclusão social e sustentabilidade ambiental são as vertentes sobre as quais o relatório foi produzido. São Paulo é a única cidade brasileira a aparecer na lista.

Nesse estudo, o quesito infraestrutura contempla um dos maiores entraves a ser enfrentado por São Paulo: a crítica situação de mobilidade dos paulistanos, que compromete severamente os outros elementos considerados no estudo, como a produtividade econômica, a qualidade de vida e o meio ambiente.

As perdas geradas pela crise da mobilidade paulistana impõem um desafio aos gestores públicos, ao setor produtivo e às instituições acadêmicas e de classe. Afinal, o desperdício de recursos por conta dos congestionamentos ultrapassa $\mathrm{R} \$ 40$ bilhões por ano.

\section{EXPANSÃO DA FROTA PAULISTANA}

Segundo o Departamento Nacional de Trânsito (Denatran), em setembro de 2012, a cidade de São Paulo contava com mais de 4,8 milhões de automóveis nas ruas, ou seja, 11,5\% da frota brasileira. Entre 2001 e 2012, a frota paulistana cresceu $54 \%$, enquanto a população da cidade cresceu $8 \%$, elevando o número de veículos por habitante de 0,30 para 0,42 no mesmo período, quase o dobro do índice nacional de 0,22.

O crescimento da quantidade de automóveis em São Paulo gera mais demanda por vias de circulação. Como sua oferta é inelástica em curto prazo e os investimentos na infraestrutura viária e no transporte coletivo de alta capacidade não foram suficientes para criar alternativas de locomoção pelo município, a crise de mobilidade tornou-se inevitável.

Além de caótico, o trânsito paulistano impõe um custo elevado e crescente para o setor produtivo, pois compromete 
severamente a produtividade da economia e o bem-estar da população. Pela sua dimensão e pelas expectativas de agravamento da situação, é imprescindível que o poder público adote uma postura mais efetiva no enfrentamento do problema.

\section{CUSTOS CAUSADOS PELO TRÂNSITO}

Os custos da mobilidade podem ser diferenciados em dois tipos: o primeiro refere-se ao tempo perdido pelas pessoas no trânsito e o segundo trata dos gastos adicionais com combustível, transporte de mercadorias e emissão de poluentes.

O custo do tempo perdido é um valor teórico e está relacionado ao uso alternativo das horas desperdiçadas pela população nos congestionamentos.

Os gastos com o congestionamento foram estimados em um estudo do Instituto de Pesquisa Econômica Aplicada (Ipea), em parceria com a Associação Nacional de Transporte Público (ANTP), considerando-se o consumo de combustível e a emissão de poluentes relacionados à velocidade de circulação dos veículos.

O custo da poluição está associado ao seu impacto sobre a saúde das pessoas. São despesas impostas à sociedade pelos efeitos dos poluentes, como doenças respiratórias, alergias, irritações de órgãos etc.

Já o gasto envolvendo o transporte de carga foi obtido considerando o volume de mercadoria transportada na cidade de São Paulo.

O estudo revela que as despesas geradas pelos congestionamentos são crescentes ao longo do tempo e passaram de $\mathrm{R} \$ 7$ bilhões em 2002 para $\mathrm{R} \$ 10$ bilhões em 2012. Já os custos do tempo perdido saltaram de $\mathrm{R} \$ 10,3$ bilhões para $\mathrm{R} \$ 30,2$ bilhões no mesmo período.

\section{O PECADO ORIGINAL DO MODELO VIÁRIO}

São Paulo é vítima de uma concepção urbanística ultrapassada. É composta por um núcleo central rodeado por centros periféricos residenciais e comerciais de segunda ordem. O sistema viário segue a mesma lógica, com a construção de grandes artérias radiais por onde o trânsito flui, na expectativa de que os veículos circulem em maiores velocidades em direção aos demais pontos paulistanos.

Se o leitor sobrevoar a cidade em um helicóptero, verificará que os congestionamentos se concentram nas principais vias arteriais e em seus acessos, ao passo que o restante das ruas fica quase sem fluxo de veículos, mesmo nos horários de pico. A perversa lógica viária arrasta os motoristas para essas vias por meio de um complexo sistema de mão e contramão, bloqueios de ruas e redes de semáforos que privilegiam as grandes correntes de tráfego. A atual estrutura induz a

\section{O DESPERDÍCIO DE RECURSOS POR CONTA DOS CONGESTIONAMENTOS EM SÃO PAULO ULTRAPASSAM R\$ 40 BILHÕES POR ANO}

execução de megaprojetos, como os gigantescos túneis, avenidas, viadutos e pontes que, no entanto, têm se revelado inúteis, pois apenas deslocam os congestionamentos para alguns metros adiante.

Vale uma comparaçãode SãoPaulo com ailha de Manhattan, em Nova Iorque. Na capital paulista, são $1.500 \mathrm{~km}^{2}$, por onde circulam quase 7 milhões de veículos, ou seja, pouco mais de 4,6 mil automóveis por $\mathrm{km}^{2}$. Em Manhattan, com área de $87,5 \mathrm{~km}^{2}$, circulam cerca de 2 milhões de veículos, ou quase 23 mil carros por $\mathrm{km}^{2}$. Mesmo tendo cinco vezes a densidade de automóveis de São Paulo, os congestionamentos lá são bem menores, pois os carros ocupam todas as vias da ilha de maneira mais ou menos homogênea, fazendo o trânsito fluir com mais velocidade.

O sistema arterial concentrador não funciona mais, pois demanda investimentos pesados em infraestrutura. Grandes obras viárias construídas nos últimos anos servem apenas para transferir os congestionamentos de um lugar para outro. Os túneis Ayrton Senna, Jânio Quadros, Faria Lima, Rebouças e a Ponte Estaiada custaram quase R\$ 3 bilhões e não geraram benefícios significativos. Se os recursos tivessem sido aplicados, por exemplo, na construção de 80 pontes sobre os rios Pinheiros e Tietê e/ou na interligação de vias que cheguem às marginais, a cidade teria uma estrutura que minimizaria os quilométricos congestionamentos.

É preciso revascularizar o trânsito. Obras de menor porte nos pontos críticos da cidade criariam um sistema integrado de circulação paralelo às grandes ruas e avenidas. Em médio prazo, teríamos uma malha de vias reticulares por toda a cidade, desconcentrando o fluxo de veículos e aproveitando melhor os mais de 16 mil km de ruas ociosas em São Paulo, exceto para o trânsito local.

Transportes coletivos, principalmente o metrô, são constantemente lembrados como a solução futura para o problema. Porém, isso exige um grande volume de recursos e não é possível esperar, pois a situação pode piorar - o custo internacional do quilômetro do metrô, por exemplo, é estimado entre R\$ 90 milhões e R\$ 180 milhões. Não se pode esperar uma solução para o trânsito paulistano apenas quando o País tiver recursos ou atrair investimentos externos. Os custos e as deseconomias atuais geradas pelas condições de 


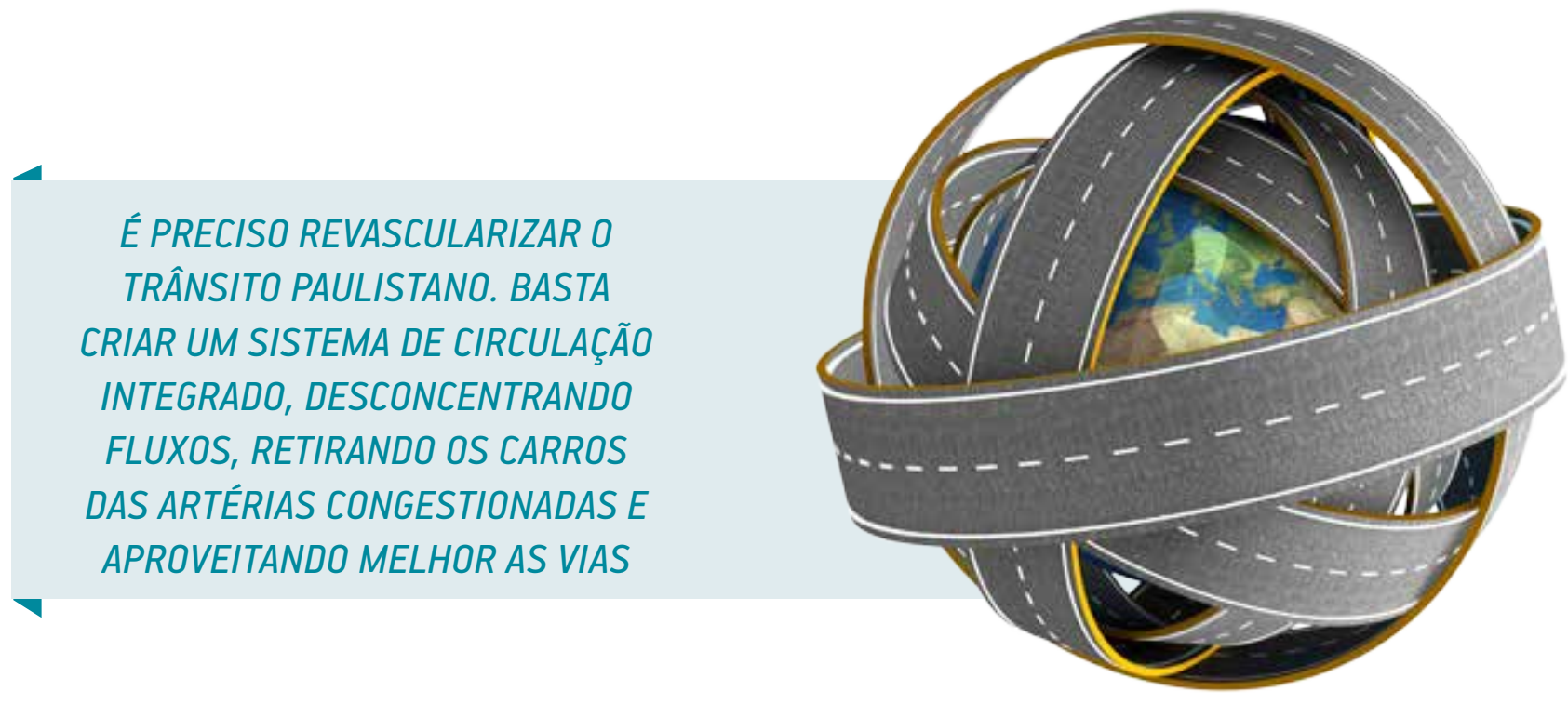

circulação na cidade restringem a capacidade de crescimento da renda, do emprego e dos investimentos.

\section{POSSÍVEIS CAMINHOS PARA DIMINUIR O PROBLEMA}

É possível empreender ações voltadas à redução dos congestionamentos até que os investimentos no transporte coletivo possam aumentar. É imprescindível que se estabeleça um conjunto de ações de curto, médio e longo prazo para aliviar o custo imposto pelos congestionamentos à sociedade.

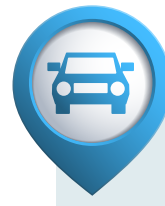

\section{AÇÕES PARA AMENIZAR O TRÂNSITO} E DIMINUIR SEU CUSTO EM SÃO PAULO

- Redirecionar os recursos canalizados em grandes obras para a revascularização do sistema viário;

- Agir com rigor na fiscalização de veículos velhos e inseguros - nas ruas paulistanas circulam até carrinhos de mão e carroças com tração animal;

- Restrição à circulação de caminhões de grande porte. O horário para transporte de carga deve ser entre 22h e 6h;

- Investir em terminais de transbordo, o que evitaria comboios de ônibus vazios em filas indianas na região central e em grandes avenidas;

- Implantar pedágios urbanos, como em Londres, Milão, Estocolmo, Cingapura e Oslo, a fim de igualar a utilidade privada ao custo social pelo uso do automóvel;

- Utilização de combustíveis não poluentes em toda a frota de ônibus;

- Desestimular a utilização de carros antigos, já que gastam maior quantidade de combustível e poluem mais, encarecendo o tributo de automóveis com mais de dez anos de uso e diminuindo o de carros novos;

- Estabelecer parcerias entre os governos federal, estadual e a iniciativa privada para acelerar a expansão da maIha metroviária;

- Investir na utilização dos 257 km de ferrovias da CPTM para a implantação de metrôs de superfície;

- Tributar o uso do veículo, e não o seu preço.

\section{CONCLUSÃO}

O desgaste dos veículos, a poluição e o aumento do consumo de combustível, gerados pelos congestionamentos, são aspectos negativos em qualquer análise econômica. Contudo, isso é minimizado quando comparado ao valor econômico das horas de trabalho desperdiçadas e à perda de qualidade de vida das pessoas, causada pelo esgotamento físico e psicológico no trânsito.

O "custo São Paulo" pressiona dramaticamente o "custo Brasil" e os congestionamentos em São Paulo não são um mero problema local, mas um gargalo nacional. A lentidão crescente nos deslocamentos implica em custos bilionários e o fato da frota de automóveis seguir em expansão preocupa e causa inquietação.

\section{PARA SABER MAIS: \\ - www.marcoscintra.org/adm/doc/Custo_Transito.pdf}

MARCOS CINTRA > Subsecretário de Desenvolvimento Econômico, Ciência e Tecnologia do Estado de São Paulo e Vice-presidente da FGV-EAESP > marcos.cintra@fgv.br 